\title{
Infection Control in the Dental Practice with Emphasis on Intraoral Scanners and Semi-Critical Complex Instruments
}

\author{
Control de Infecciones en la Práctica Dental Con Énfasis en \\ Escáneres Intraorales e Instrumentos Complejos Semicríticos
}

\author{
Carolina Soto-Álvarez 1,2; Gabriel M. Fonseca1; Inmaculada Alemán³ \& Sandra López-Lázaro1,4
}

SOTO-ÁLVAREZ, C.; FONSECA, G. M.; ALEMÁN, I. \& LÓPEZ-LÁZARO S. Infection control in the dental practice with emphasis on intraoral scanners and semi-critical complex instruments. Int. J. Odontostomat., 14(4):694-700, 2020.

\begin{abstract}
We present an integrative review of the literature conducted to find and analyse specific measures for disinfection and/or sterilization of intraoral complex instruments, applicable to intraoral scanners. We performed a two-stage search in the PubMed/MEDLINE, SciELO, REDALYCS, and LILACS databases, and the Google Scholar website, which included full articles in Spanish, Portuguese, and English. The strategy associated the terms 'disinfection', 'biosecurity', 'decontamination', and (a) 'intraoral scanners', and (b) other 'semi-critical' intraoral complex instruments, according to the American Dental Association definition (e.g., 'turbine', etc). Strategy (a) produced just one outcome, whereas (b) produced nine articles, which only suggested low-level disinfectants. The lack of empirically based protocols that allow effective microbiological control makes it necessary to create a new categorization for these instruments when trying to comply with American Dental Association recommendations for dental practice.
\end{abstract}

KEY WORDS: Disinfection; Sterilization; Decontamination; Safety; Equipment.

\section{INTRODUCTION}

For odontologists, the health and safety of their patients is of fundamental importance, so keeping them protected from potential sources of cross-contamination and possible infection is a priority axis of their health care (The Digital Stream, 2020). During dental treatment, exposure to pathogens can be caused by contact with blood, oral and respiratory secretions, and contaminated equipment. Universal precautionary measures are based on the concept that all blood and certain body fluids should be considered infectious since it is impossible to know who might be a carrier of a blood-borne virus. Thus, universal precautionary measures should be applied to all patients (Sebastiani et al., 2017).

About 50 years ago, Spaulding (1968) proposed a categorization for reusable devices according to the degree of infection risk involved in their use: critical (enters sterile tissue and must be sterile), semi-critical (contacts mucous membranes and requires high-level disinfection), and non-critical (contacts intact skin and requires low-level disinfection). The Centers for Disease Control and Prevention (CDC), the leading national public health institute of the United States devoted to protecting public health and safety through the control and prevention of disease, injury, and disability in the US and internationally (www.cdc.gov), in its Summary of Infection Prevention Practices in Dental Settings, includes among the semi-critical items very heterogeneous devices such as mouth mirrors, amalgam condensers, reusable dental impression trays, dental handpieces and associated attachments (including low-speed motors and reusable prophylaxis angles), and digital radiography sensors. The CDC's

\footnotetext{
${ }^{1}$ Forensic Dentistry Lab, Centro de Investigación en Odontología Legal y Forense -ClO-, Facultad de Odontología, Universidad de La Frontera, Temuco, 4780000, Chile.

2 Master's program in Dentistry, Facultad de Odontología, Universidad de La Frontera, Temuco, 4780000, Chile.

${ }^{3}$ Laboratory of Anthropology, Department of Legal Medicine, Toxicology and Physical Anthropology, School of Medicine, University of Granada, Granada, 18016, Spain.

${ }^{4}$ Departamento de Antropología, Facultad de Ciencias Sociales, Universidad de Chile, Av. Ignacio Carrera Pinto 1045, 685033, Santiago, Chile. Financiado por: ANID PFCHA/Magíster Nacional/2018-22172333; ANID FONDECYT 11.160.487; ANID MEC 80.170.077.
} 
guidelines for sterilizing such devices require the use of heat and if the item is heat-sensitive, they require the use of a high-level disinfectant to meet the minimum standard of care. If the item cannot tolerate these procedures, an FDA-cleared barrier must be used at least, or reference should be made to the manufacturer's instructions for reprocessing (Centers for Disease Control and Prevention, 2016).

Nowadays, there is growing use of hightechnology tools in the dental field. Computer-aided design/computer-aided manufacturing (CAD/CAM) was used for the first time in odontology in the late '70s, and over the years, technological refinement, miniaturization, and entry to the market of handheld scanners and intraoral digital devices has completely changed the scene of the dental office and the role that intraoral scanners play in patient satisfaction and retention (Waugh, 2017): according to a 2016 survey by the Journal of Clinical Orthodontics, $62 \%$ of respondents said they routinely use an intraoral scanner in their offices. The use of intraoral scanners is an increasing phenomenon in many areas of dentistry (Sfondrini et al., 2018), as other instruments for intraoral use-intraoral cameras and apex locators, among others-have diversified their use in all areas of clinical practice. Although the CDC does not explicitly mention them, it has been suggested that these 'intraoral complex instruments' (IOCls) must also be considered semi-critical because of their obvious contact with mucous membranes or non-intact skin (The Digital Stream).

Blázquez-Garrido et al. (2018) stated that it is semi-critical devices that have been most frequently associated with the appearance of infections during health care. The disinfection process necessary for reuse between patients is a high-level process that in many cases is complicated not only by the structural complexity of the devices but also because it is a laborious process with different stages very dependent on proper training of the health personnel in charge of carrying it out (Blázquez-Garrido et al.). Although this problem has been given significant attention in medicine (Rutala \& Weber, 2019), it does not seem to have the same considerations in dentistry.

Intraoral scanners are among these IOCls. As they have progressively increased in popularity, more questions have arisen regarding the correct sterilization procedures (The Digital Stream). Their undivided design features are a disadvantage with respect to their structure, given that using non-removable nozzles does not allow their sterilization by conventional methods (Condor Intra-Oral Scanner, 2018). Although the schemes proposed by Spaulding still remain valid, disinfection strategies for some semi-critical items are highly variable and, in many cases, an obvious challenge (Rutala \& Weber, 2019).

In 2015, Perea-Pérez et al. reported two cases of transmission of viral diseases during dental care (hepatitis B and C) with serious consequences, including one with death due to acute hepatitis. This determined that 'check the procedures for cleaning, disinfection, sterilization, and preservation of clinical instruments' is considered by the authors as one of the 11 basic procedures/practices for dental patient safety. The authors emphasize that using clear and wellestablished protocols is essential in order to inform and train the personnel in charge of these procedures, 'ensuring their proficiency and awareness of the importance of these tasks' and preventing 'possible misconceptions the staff may have' (Perea-Pérez et al.).

Since the use of $10 \mathrm{Cls}$ requires contact with mucous membranes, teeth, oral fluids, and other biological materials, and because of their characteristics, it is necessary to reformulate suitable patient safety measures for clinical use. We present a review of the literature conducted to find and analyse specific measures for disinfection and/or sterilization applicable to intraoral scanners and other IOCls.

\section{MATERIAL AND METHOD}

This review was conducted following PRISMA (Preferred Reporting for Systematic Reviews and MetaAnalyses) guidelines. We performed a systematic search in the PubMed/MEDLINE, SciELO, REDALYCS, and LILACS databases, with complementary use of the Google Scholar website, searching for full articles in Spanish, Portuguese, and English, which were independently analysed by two researchers, between 30th July 2017 and 31st December 2018. The review of the literature was carried out to find and analyse specific measures for disinfection and/or sterilization of intraoral scanners and other IOCls. To cover the entire possible universe of alternatives related to the subject of this review, we used a strategy that associated the terms 'disinfection', 'biosecurity', and 'decontamination', and (a) 'intraoral scanners' in the first stage, and (b) other 'semi-critical' $\mathrm{IOCls}$, according to the American Dental Association 
definition (e.g., 'turbine', 'radiovisiograph', 'intraoral camera', 'halogen dental lamp', 'apex locator', 'endoscope') in the final stage of the search. When we expanded the search, it was possible to assess the existence of protocols for other instruments that could be of great help for implementing or developing disinfection protocols that can be applied or implemented for intraoral scanners.

\section{RESULTS}

In the first stage, we only found one study, and in the second stage we found nine studies (Fig. 1; Table I).

IOCls (Table I): Regarding the IOCls under study, five articles mentioned high-speed handpieces (55.56 $\%)$, two articles mentioned semi-critical instruments $(22.22 \%)$, one article mentioned phosphor plates for intraoral digital radiographs $(11.11 \%)$, and one article mentioned light-curing lamps (11.11\%).
Authors' country of origin (Table I): With respect to the countries the researchers were from, three were from the United States (33.3 \%), two from Brazil (22.2 $\%)$, one from Italy, one from Denmark, one from Scotland, and one from Canada.

Year of publication (Table I): Of all the studies, four had been conducted in the last 3 years, mostly during 2017, which corresponded to $44.4 \%$.

Profile of the publication (Table I): We found four publications in the field of infectiology and microbiology (Infectious Disease Clinics of North America, American Journal of Infection Control, and Journal of Clinical Microbiology), three in the field of dental practice (British Dental Journal and Journal of Clinical Periodontology), one in the field of radiology (Dentomaxillofacial Radiology), and one in a medical journal (Revista Latino-Americana de Enfermagem).

Outcomes (Table I): Most of the studies (66.7 $\%$ ) reported the importance of $\mathrm{IOCI}$ sterilization due to

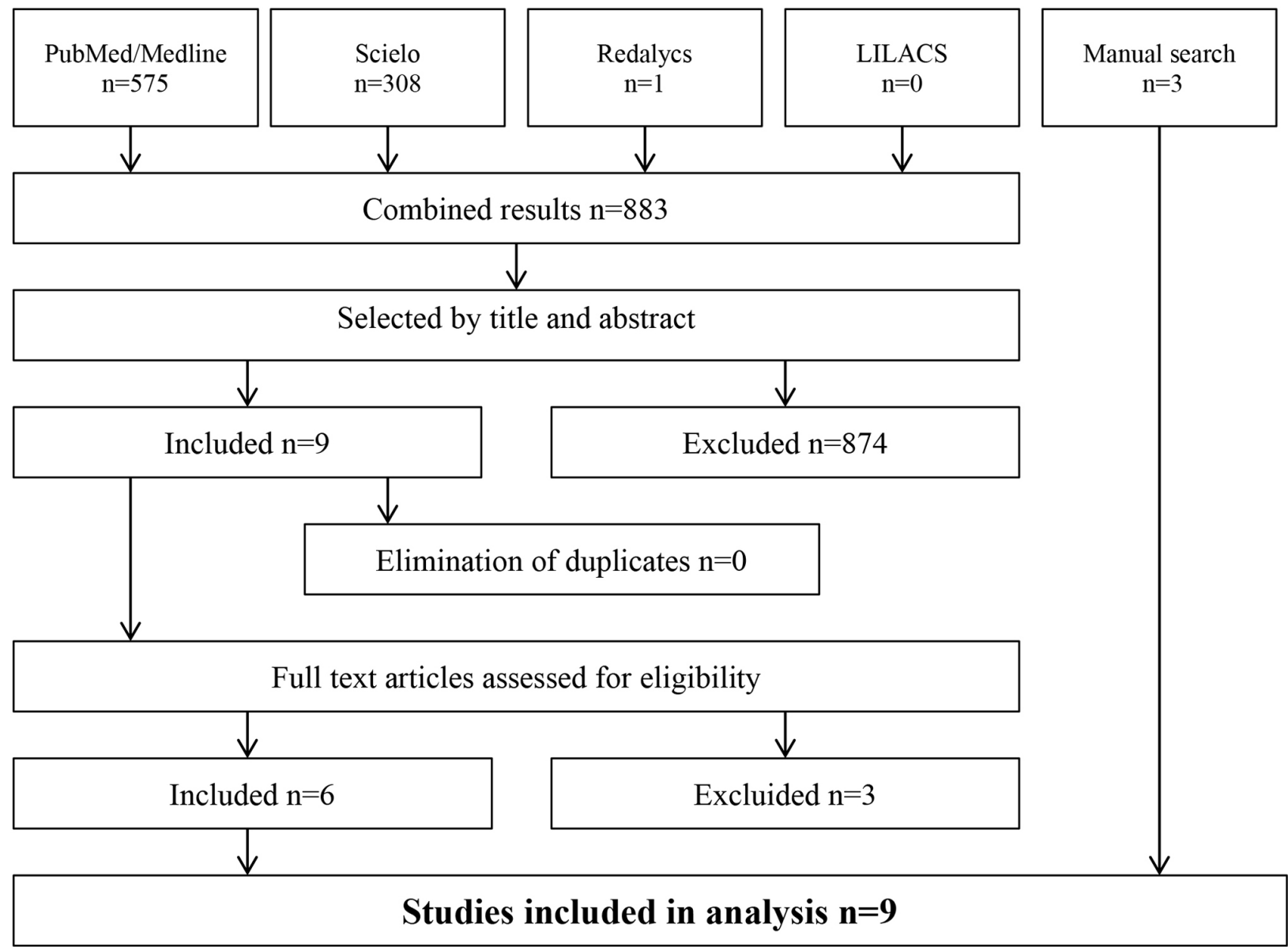

Fig. 1 Study selection process. 
the risk of cross-infection. We observed that there were protocols commonly used to process equipment prior to sterilization, but they were not validated. External disinfection of the instruments does not guarantee the absence of microorganisms, so they should always undergo cleaning procedures prior to conventional sterilization processes. Although the professionals who perform these procedures are aware of the risk of possible contamination, they do not always comply with the established standards for the treatment of complex intraoral devices or for the activity of some disinfectants on surfaces.

Table I. Summary of included studies, countries of their authors, instruments used, journals of publication, and published outcomes.

$\begin{array}{llll}\text { Study included } & \begin{array}{l}\text { Authors' } \\ \text { country of } \\ \text { origin }\end{array} & \text { Journal of publication } & \text { IOCI }\end{array} \quad$ Outcomes

Lewis and Boe (1992)

USA

Journal of clinical Microbiology

Checchi et al. (1998)

Italy

Journal of Clinic al

Periodontology

Smith et al. (2009)

Scotland

British Dental Journal

Rutala and Weber (2011)

USA

Infectio us Disease Clinics of North America

Wenzel et al. (2013)

Ribeiro et al. (2009)

Brazil

Revista Latino-Americana de Enfermagem

Shortall et al. (2016)

Canada

British Dental Journal

American Journal of

Acosta-Gio et al. (2017)

USA Infection Control

Pinto et al. (2017)
Brazil
American Journal of Infection Control radiographs
Turbine

Turbine

Turbine

Unless reliable data on the frequencies of cross-infection were obtained, and it was shown that heat cleaning and sterilization of the turbines was not necessary between patients, an essential component of the standard procedures for universal precautions in biosecurity should be taken into consideration.

There is potential crosscontamination when the turbines are externally disinfected, this way, sterilization is mandatory.

Most of the dentists surveyed sterilized the turbine after being used in each patient. There were not adequate disinfection protocols prior to sterilization.

The results of the infection control
Halogen lamp

Critical, semicritical, noncritical

Phosphor plates for

Semi-critical

Turbine rounds should be provided to unit managers. Reprocessing deficiencies should be corrected and measures should be documented for infection control within two weeks.

$82 \%$ e thanol with $0.5 \%$ chlorhexidine gluconate and glycerol eliminated all microorganisms, whereas 2-propanol did not.

Disinfection of semi-critical materials using $70 \%$ alcohol or similar concentrations is usually unsafe. Prior cleaning of the instrument and its complexity may vary the results.

The gold standard is the sterilization of the tip of the lamp and the disinfection of the rest of the equipment. The use of a protective case reduces the power of light output by approximately $10 \%$.

Surface disinfection or immersion in disinfectant substances are not acceptable methods for dental hand pieces. Therefore, compliance with sterilization remains a challenge in dental practice.

The survival of microorganisms refutes the practice of turbines decontamination by rubbing with $70 \%$ alcohol for 90 seconds in the absence of prior cleaning. 


\section{DISCUSSION}

The Digital Stream stated that, even following the CDC recommendations for sterilization of semicritical instruments (Centers for Disease Control and Prevention, 2016), the individual conditions for each $\mathrm{IOCl}$ will determine the possibility or not of achieving the minimum standard of care. In the particular case of the intraoral scanner-which is heat-sensitive-the possibility of disassembling its tip (not available for all devices) and immersing it in a sporicidal chemical or sterilizing it in an autoclave would configure the best scenario. However, the author mentions that 'some intraoral scanner manufacturers advise against both autoclaving and immersion in a disinfecting chemical and, instead, instruct users to wipe the scanner tip down with a cloth that has been immersed in the prepared solution. As the scanner tip is a semicritical instrument, these instructions do not meet even the minimum standard of best practices for infection control-leaving patients vulnerable to infection as a result'. These possibilities are absolutely market-dependent (The Digital Stream), and in complex cases, even the CDC refers to the 'manufacturer's instructions for reprocessing' (Centers for Disease Control and Prevention, 2016).

Osegueda-Espinosa et al. (2017) reported that, even in controlled and training settings, only $35 \%$ of 207 dentists stated that they were compelled to sterilize handpieces between patients. As seen, although checking the procedures for cleaning, disinfection, sterilization, and preservation of clinical instruments is considered a basic procedure for dental patient safety (Perea-Pérez et al.), monitoring of procedures to ensure that these operations are performed according to established protocols is still an unfortunately uncommon safe practice. Moreover, the use of these technologies is clearly on the rise and their implementation in areas of dental research is more than evident (Abduo \& Elseyoufi, 2018).

The results of the present literature review, carried out in two stages to expand the search field, revealed a lack of protocols for the management of patient safety norms relating to $\mathrm{IOCls}$ in general, and intraoral scanners in particular. Despite the increase in use of intraoral scanners in clinical practice and research, only one article was found in the first stage; in the second stage, we only found one article that had addressed the management of biosecurity norms for other $1 \mathrm{OCls}$. It is important to emphasize that disinfection or sterilization protocols for other IOCls can be used for the development and implementation of protocols for intraoral scanners.

According to the data found in the literature, the largest number of studies analysed in the present review addressed the disinfection or sterilization processes of turbines, light-curing lamps, and radiographic phosphor plates; however, we did not find studies addressing intraoral scanners that validated, or at least mentioned, processes of disinfection or treatment of surfaces for these devices that ensured compliance with biosecurity.

Currently, the Environmental Protection Agency (EPA) and the Food and Drug Administration (FDA) classify $70 \%$ or $90 \%$ alcohol as a low-level disinfectant (Rutala \& Weber, 2004, 2011), which is not enough for the management of semi-critical instruments or equipment, since it does not guarantee the complete elimination of microorganisms (Pereira et al., 2008; Ribeiro et al., 2015), because there may be microbial groups resistant to alcohol (Pinto et al., 2017). In spite of this, the commonly recommended process to disinfect $\mathrm{IOCls}$ for clinical practice is the use of alcohol at a concentration of $70 \%$ as an external disinfectant (Pereira et al.; Ribeiro et al.), always after a cleaning process in cases that they are subjected to high-level disinfection or sterilization (Rutala \& Weber, 2004, 2011).

Although alcohol is the most recommended disinfectant, there is still no agreement on its classification. Some authors classify it as an intermediate-level disinfectant (Pereira et al.; Centers for Disease Control and Prevention, 2008), whereas others classify it as a low-level disinfectant (Rutala \& Weber, 2004; Pereira et al.). It is also worth mentioning the limited action of the disinfectant agent when there are associated factors, such as in the case of the design of handpieces in their external conformation (Smith et al., 2009). Pinto et al. pointed out the presence of organic remains (saliva or others) on the external surfaces of instruments or equipment as another reason that hinders the action of alcohol, since they are protected against the action of disinfectants or sterilization processes. Therefore, the literature indicates that it is possible to obtain better outcomes during disinfection processes if cleaning is performed prior to disinfection, given that if there are no organic remains on the surface, there will be a lower microbial load, which favours the action of the disinfecting agent (Pinto et al.). 
Although all these guidelines should be applied in the management of biosecurity of $\mathrm{IOCls}$, their design and components prevent conventional sterilization, thus making the use of a correct disinfection protocol essential. According to the ADA classification, the only correct process is high-level disinfection, since low- or intermediate-level disinfection is not enough (Rutala \& Weber, 2013). Rutala \& Weber (2011) stated that, even using iodoform, alcohol, or glutaraldehyde diluted as high-level disinfectants, the proliferation of microorganisms on the surfaces persists. This is why we agree with Checchi et al. (1998) and Lewis \& Boe (1992) who emphasized the concept that dental devices, such as turbines, low-speed motors, reusable inserts, and associated accessories, should be sterilized between use with each patient, and not only submitted to high-level disinfection if they have had contact with oral fluids (Rutala \& Weber, 2013). In addition, we agree with Rutala \& Weber $(2011,2013)$ on the importance of performing adequate disinfection and sterilization, because these procedures guarantee the safe use of invasive and non-invasive instruments.

In the case of halogen lamps, it is important to highlight the study conducted by Shortall et al. (2016) who pointed out that the gold standard for biosecurity in these instruments corresponds to sterilization of the tip and disinfection of the rest of the equipment. With respect to phosphor plates for digital radiography, Thomas \& Abramovitch (2005) and Hokett et al. (2000) stated that they should have a protective cover and be disinfected after use. They also mentioned that $70 \%$ alcohol damages the film and recommended using a mixture of $82 \%$ ethanol with $0.5 \%$ chlorhexidine gluconate and glycerol, which is more effective than 2-propanolol. They also mention that the use of UV-light (which generates DNA and RNA alterations leading to irreversible damage and killing of microorganisms; Russotto et al., 2017) as a disinfectant is effective for the elimination of microorganisms, but it increases the waiting time for a new scan. Therefore, it would be interesting to be able to delve into this type of new techniques, since apparently they do not cause harm to the plates, even though they are only available for some digital devices.

We agree with Pinto et al. when they affirmed that the existing risk due to non-compliance with biosecurity regulations for the management of devices in the dental field is widely recognized, even though there is a lack of validated protocols and incomplete compliance with established norms by health workers in charge of carrying out these procedures. Therefore, it is necessary to point out the lack of established protocols for high-level disinfection of complex intraoral equipment, since the literature only refers to intermediate- or low-level disinfection, and not to more efficient processes to guarantee biosecurity. It is unavoidable to be aware that some intraoral devices can be used as critical or semi-critical instruments, which creates a challenge for the operators, since it is necessary to comply with management standards for clinical use. This suggests the importance of developing protocols for the treatment of semi-critical devices or a new ADA classification for these instruments. Rutala \& Weber (2019) affirmed that it is extremely important to adopt control measures to avoid exposure of patients to pathogens, and that it is precisely semi-critical equipment that has mostly been associated with reprocessing errors. Although most of the time the current recommendations suggest referring to the manufacturer's instructions to be able to reprocess IOCls (Centers for Disease Control and Prevention, 2016), there are currently no established protocols for new equipment to ensure access to this information (according to the FDA, the device manufacturer must include at least one validated cleaning and disinfection and sterilization protocol in the labelling for their device) (Rutala \& Weber, 2019), nor alternatives that allow adherence to these recommendations for many of the devices available in the market, nor mechanisms to train staff on the safe use and reprocessing of IOCls (Blázquez-Garrido et al.; Rutala \& Weber, 2019).

We concur with Barenghi et al. (2019) in that guidelines for infection prevention using CAD/CAM technology have not been updated, and that odontologists and dental caregivers need better instructions for use and transparency from manufacturers. The presence of an infection coordinator is essential to follow instructions for use, as well as good planning for prevention of infections.

\section{CONCLUSIONS}

In the present study, we did not find adequate protocols for performing effective microbiological control in IOCls. Therefore, it is necessary to implement a new categorization for these instruments, in order to comply with the $\mathrm{CDC}$ recommendations.

ACKNOWLEDGMENTS. ANID PFCHA/Magíster Nacional/2018-22172333; ANID FONDECYT 11.160.487; ANID MEC 80.170.077. 
SOTO-ÁLVAREZ, C.; FONSECA, G. M.; ALEMÁN, I. \& LÓPEZLÁZARO S. Control de infecciones en la práctica dental con énfasis en escáneres intraorales e instrumentos complejos semicríticos. Int. J. Odontostomat., 14(4):694-700, 2020.

RESUMEN: Presentamos una revisión integradora de la literatura realizada para encontrar y analizar medidas específicas de desinfección y / o esterilización de instrumentos complejos intraorales, aplicables a los escáneres intraorales. Realizamos una búsqueda en dos etapas en las bases de datos PubMed / MEDLINE, SciELO, REDALYCS y LILACS, y en el sitio web Google Scholar, que incluía artículos completos en español, portugués e inglés. La estrategia asoció los términos 'desinfección', 'bioseguridad', 'descontaminación' y (a) 'escáneres intraorales', y (b) otros instrumentos complejos intraorales 'semicríticos', según la definición de la Asociación Dental Americana (p. Ej., 'turbina', etc.). La estrategia (a) produjo un solo resultado, mientras que (b) produjo nueve artículos, que solo sugirieron desinfectantes de bajo nivel. La falta de protocolos de base empírica que permitan un control microbiológico efectivo hace necesario crear una nueva categorización para estos instrumentos, cuando se trata de cumplir con las recomendaciones de la Asociación Dental Americana para la práctica dental.

PALABRAS CLAVE: Desinfección; Esterilización; Descontaminación; Seguridad; Equipamiento.

\section{REFERENCES}

Abduo, J. \& Elseyoufi, M. Accuracy of intraoral scanners: a systematic review of influencing factors. Eur. J. Prosthodont. Restor. Dent., 26(3):101-21, 2018.

Barenghi, L.; Barenghi, A.; Cadeo, C. \& Di Blasio, A. Innovation by computer-aided design/computer-aided manufacturing technology: a look at infection prevention in dental settings. Biomed. Res. Int., 2019:6092018, 2019.

Blázquez-Garrido, R. M.; Cuchí-Burgos, E.; Martín-Salas, C. \& RuizGarbajosa, P. Métodos microbiológicos para la monitorización de la limpieza, desinfección y esterilización de dispositivos médicos. Enferm. Infecc. Microbiol. Clin., 36(10):657-61, 2018.

Centers for Disease Control and Prevention (CDC). Guideline for Disinfection and Sterilization in Healthcare Facilities. Atlanta, Centers for Disease Control and Prevention, 2008. Available from: https://www.cdc.gov/infectioncontrol/guidelines/disinfection/ index.html

Centers for Disease Control and Prevention (CDC). Summary of Infection Prevention Practices in Dental Settings. Atlanta, Centers for Disease Control and Prevention, US Dept of Health and Human Services, 2016. Available from: https://www.cdc.gov/oralhealth/ infectioncontrol/summary-infection-prevention-practices/index.html

Checchi, L.; Montebugnoli, L. \& Samaritani, S. Contamination of the turbine air chamber: a risk of cross infection. J. Clin. Periodontol., 25(8):607-11, 1998.

Condor Intra-Oral Scanner. Web Site. Condor Intra-Oral Scanner, 2018. Available from: https://www.condorscan.com

Hokett, S. D.; Honey, J. R.; Ruiz, F.; Baisden, M. K. \& Hoen, M. M. Assessing the effectiveness of direct digital radiography barrier sheaths and finger cots. J. Am. Dent. Assoc., 131(4):463-7, 2000.

Lewis, D. L. \& Boe, R. K. Cross-infection risks associated with current procedures for using high-speed dental handpieces. J. Clin. Microbiol., 30(2):401-6, 1992.
Osegueda-Espinosa, A. A.; Sánchez-Pérez, L.; Perea-Pérez, B.; LabajoGonzález, E. \& Acosta-Gio, A. E. Dentists survey on adverse events during their clinical training. J. Patient Saf., 2017. DOI: https:// www.doi.org/10.1097/PTS.0000000000000296

Perea-Pérez, B.; Labajo-González, E.; Acosta-Gío, A. E. \& Yamalik, N. Eleven basic procedures/practices for dental patient safety. J. Patient Saf., 16(1):36-40, 2015.

Pereira, R. S.; Tripple, A. F. V.; Reis, C.; Cavalcante, F. O. \& Belo, T. K. Á. M.C. Influencia do acesso endodontico na localizacao dos canais radiculares dos molares superiores. ROBRAC,17:124-32, 2008.

Pinto, F. M. G.; Bruna, C. Q. M.; Camargo, T. C.; Marques, M.; Silva, C. B.; Sasagawa, S. M.; Mimica, L. M. J. \& Graziano, K. U. The practice of disinfection of high-speed handpieces with $70 \%$ w/v alcohol: An evaluation. Am. J. Infect. Control, 45(1):e19-e22, 2017.

Ribeiro, M. M.; Neumann, V. A.; Padoveze, M. C. \& Graziano K. U. Efficacy and effectiveness of alcohol in the disinfection of semi-critical materials: a systematic review. Rev. Lat. Am. Enfermagem.,23(4):74152, 2015.

Russotto, V.; Cortegiani, A.; Fasciana, T.; lozzo, P.; Raineri, S. M.; Gregoretti, C.; Giammanco, A. \& Giarratano, A. What healthcare workers should know about environmental bacterial contamination in the intensive care unit. Biomed. Res. Int., 2017:6905450, 2017.

Rutala, W. A. \& Weber, D. J. Disinfection and sterilization in health care facilities: what clinicians need to know. Clin. Infect. Dis., 39(5):702-9, 2004.

Rutala, W. A. \& Weber, D. J. Disinfection and sterilization: an overview. Am. J. Infect. Control, 41(5 Suppl.):S2-5, 2013.

Rutala, W. A. \& Weber, D. J. Reprocessing semicritical items: Outbreaks and current issues. Am. J. Infect. Control, 47S:A79-A89, 2019.

Rutala, W. A. \& Weber, D. J. Sterilization, high-level disinfection, and environmental cleaning. Infect. Dis. Clin. North Am., 25(1):45-76, 2011.

Sebastiani, F. R.; Dym, H. \& Kirpalani, T. Infection control in the dental office. Dent. Clin. North Am., 61(2):435-57, 2017.

Sfondrini, M. F.; Gandini, P.; Malfatto, M.; Di Corato, F.; Trovati, F. \& Scribante, A. Computerized casts for orthodontic purpose using powder-free intraoral scanners: accuracy, execution time, and patient feedback. Biomed. Res. Int., 2018:4103232, 2018.

Shortall, A. C.; Price, R. B.; MacKenzie, L. \& Burke, F. J. T. Guidelines for the selection, use, and maintenance of LED light-curing units - Part II. Br. Dent. J.,221(9):551-4, 2016.

Smith, G. W. G.; Smith, A. J.; Creanor, S.; Hurrell, D.; Bagg, J. \& Lappin, D. F. Survey of the decontamination and maintenance of dental handpieces in general dental practice. Br. Dent. J., 207(4):E7, 2009.

Spaulding, E. Chemical Disinfection of Medical and Surgical Materials. In: Lawrence, C. B. S. (Ed.). Disinfection, Sterilization, and Preservation. Philadelphia, Lea and Febiger, 1968. pp.517-31.

The Digital Stream. Does your intraoral scanner meet best practices for infection control?. Web Site. Carestream Dental, 2020. Available from: https://www.carestreamdental.com/en-au/training-resources/thedigital-stream/english/americas/2020/does-your-intraoral-scannermeet-best-practices-for-infection-control/

Thomas, L. P. \& Abramovitch, K. Infection control for dental radiographic procedures. Tex. Dent. J., 122(2):184-8, 2005.

Waugh, R. An Analysis of the Impact of Intraoral Scanners on the Orthodontic Practice. Web Site. Scottsdale, Orthodontic Practice US, 2017. Available from: https://www.orthopracticeus.com/ce-articles/ analysis-impact-intraoral-scanners-orthodontic-practice

Corresponding author:

Sandra López-Lázaro

Francisco Salazar 01145

Building L.

Temuco -CHILE

Email: sandra.lopez.l@ufrontera.cl

Received: 27-03-2020

Accepted :01-05-2020 